\title{
Bio-Based Succinate Production from Arundo donax Hydrolysate with the New Natural Succinic Acid-Producing Strain Basfia succiniciproducens BPP7
}

\author{
Valeria Ventorino $^{1} \cdot$ Alessandro Robertiello $^{1} \cdot$ Donatella Cimini $^{2} \cdot$ Ottavia Argenzio $^{2}$. \\ Chiara Schiraldi $^{2}$ - Salvatore Montella ${ }^{3}$ - Vincenza Faraco ${ }^{3}$ - Annamaria Ambrosanio ${ }^{1}$. \\ Sharon Viscardi ${ }^{1}$ - Olimpia Pepe ${ }^{1}$
}

Published online: 21 January 2017

(C) The Author(s) 2017. This article is published with open access at Springerlink.com

\begin{abstract}
Bio-based succinic acid production from lignocellulosic biomass is one of the attractive and prominent alternative technologies to overcome issues associated with the utilization of fossil sources. In this context, it is necessary to find new microorganisms that are able to efficiently ferment this recalcitrant feedstock. The ecological approach developed in this study enabled the isolation of Basfia succiniciproducens BPP7 from a complex rumen ecosystem. This new wild-type strain was able to synthesize up to $6.06 \pm 0.05 \mathrm{~g} / \mathrm{L}$ of succinate (corresponding to $0.84 \pm 0.017 \mathrm{~g}$ of succinate per gram of consumed glucose + xylose and to $0.14 \pm 0.001 \mathrm{~g}$ of succinate per gram of glucans + xylans present in the biomass before hydrolysis) from Arundo donax hydrolysate in separate hydrolysis and fermentation (SHF) experiments. Higher titers of succinic acid were obtained through the optimization of growth conditions. The optimal medium composition identified on the smaller scale was then used for 2.5-L batch experiments, which used A. donax hydrolysate and yeast extract as the main $\mathrm{C}$ and $\mathrm{N}$ sources, respectively. A maximal titer of $9.4 \pm 0.4 \mathrm{~g} / \mathrm{L}$ of succinic acid was obtained after $24 \mathrm{~h}$. The overall results clearly demonstrate the potential of B. succiniciproducens BPP7 for succinate production.
\end{abstract}

Olimpia Pepe

olipepe@unina.it

1 Department of Agricultural Sciences, Division of Microbiology, University of Naples Federico II, Via Università 100, 80055 Portici, Naples, Italy

2 Department of Experimental Medicine, Section of Biotechnology Medical Histology and Molecular Biology, Second University of Naples, Via de Crecchio 7, 80138 Naples, Italy

3 Department of Chemical Sciences, University of Naples Federico II, Complesso Universitario Monte S. Angelo, Via Cintia 4, 80126 Naples, Italy
Keywords Basfia succiniciproducens $\cdot$ Lignocellulosic biomass $\cdot$ Arundo donax $\cdot$ Succinic acid $\cdot$ Fermentation

\section{Introduction}

Succinic acid (SA) $\left(\mathrm{C}_{4} \mathrm{H}_{6} \mathrm{O}_{4}\right)$ is widely used as a precursor for many important chemicals for a broad range of industrial applications, such as the manufacture of solvents, biodegradable plastics, pharmaceuticals, and polymers [1]. Today, SA is primarily produced by chemical processes from the hydrogenation of maleic anhydride to succinic anhydride, followed by hydration to SA [2]. However, due to the high production cost and environmental concerns, there is growing interest in the synthesis of SA based on biological routes, as this dicarboxylic acid is produced as an intermediate of the Krebs cycle or as a product of anaerobic metabolism in microbial fermentations [3]. Many different microorganisms, such as Aspergillus spp., Byssochlamys nivea, Saccharomyces cerevisiae, Anaerobiospirillum succiniciproducens, Actinobacillus succinogenes, Mannheimia succiniciproducens, Basfia succiniciproducens, Fibrobacter succinogenes, Ruminococcus albus, Prevotella ruminicola, Bacteroides amylophilus, and Bacteroides fragilis, isolated from the rumen and other environments, have been assayed and studied for their SA production potential [3, 4]. Additionally, recombinant Escherichia coli strains have been developed to enhance SA production under aerobic and anaerobic conditions [5]. However, bacteria isolated from the rumen are reported as the best SA producers. In fact, high amounts of this $\mathrm{C} 4$ dicarboxylic acid are synthesized by $\mathrm{CO}_{2}$ fixation reactions. The products of these reactions can be converted into propionic acid, providing energy and biosynthetic precursors for the animals [6]. There are different metabolic pathways leading 
to SA synthesis. In particular, most bacteria use the phosphoenolpyruvate (PEP) carboxylation reaction (i.e., A. succiniciproducens) [6], whereas others, such as M. succiniciproducens [3, 7], use multiple pathways.

Renewable carbon sources to use in microbial fermentations represent the most prominent eco-technological strategy for bio-based succinate production [8]. One of the most abundant renewable sources is represented by lignocellulosic biomass, including dedicated energy crops such as miscanthus, switchgrass, Arundo donax (giant reed), Populus nigra (poplar), and Eucalyptus camaldulensis (river red gum). These plants can be easily grown in lands not suitable for food crops such as soils that are poor, degraded, or subjected to accelerated erosion $[9,10]$. Therefore, due to the abundance and cheapness of raw materials, the use of lignocellulosic biomass hydrolysate is a very attractive and sustainable technology for SA production [1], which may result in processes that are cheaper than petroleum-based processes [6]. Additionally, to satisfy the increasing demand for plastics and to reduce the dependency of plastics on fossil fuels, the development of biopolymers and bio-based plastics from renewable resources is increasing [11].

In the present work, an ecological approach to isolate potential SA-producing bacteria from natural ecosystems was developed. In particular, two SA producer strains, belonging to the $B$. succiniciproducens species, with an attractive substrate utilization spectrum were isolated and tested for their capacity to synthesize succinate from A. donax-pretreated lignocellulosic biomass. The optimization of some process parameters, such as agitation and $\mathrm{CO}_{2}$ sparging, and medium composition were also considered for increasing SA production, together with the implementation of the batch process in 2.5-L fermenters.

\section{Materials and Methods}

\section{Isolation and Identification of Bacterial Strains}

Rumens and rumen contents were obtained from 14 freshly slaughtered cattle samples that differed in age, gender, and origin (Table 1). An aliquot $(10 \mathrm{~g})$ from each sample was inoculated in $200 \mathrm{~mL}$ of minimum salt enrichment medium (MSEM) supplemented with $0.016 \mathrm{~g} / \mathrm{L}$ lasalocid (SigmaAldrich, Milan, Italy) and $0.010 \mathrm{~g} / \mathrm{L}$ of monensin (SigmaAldrich) [3]. The enrichment cultures were incubated at $37{ }^{\circ} \mathrm{C}$ in an atmosphere with $5 \% \mathrm{CO}_{2}\left(\mathrm{CO}_{2}\right.$ incubator NOVACELL CO 170, Esco CelCulture Incubator, Italy) for $18 \mathrm{~h}$ and were serially decimally diluted (up to $10^{-7}$ ) in phosphate-buffered saline solution (PBS) and in LuriaBertani (LB) liquid medium (10 g/L tryptone, $5 \mathrm{~g} / \mathrm{L}$ yeast extract, $10 \mathrm{~g} / \mathrm{L} \mathrm{NaCl}, \mathrm{pH}$ 7.0). One hundred microliters of each PBS dilution was spread on two solid selective isolation
Table 1 Features of the bovine rumen samples used in this study

\begin{tabular}{llrl}
\hline Sample & Breed & Age (years) & Breeding location \\
\hline A & Female buffalo & 5 & Potenza \\
B & Female buffalo & 4 & Matera \\
C & Steer & 6 & Potenza \\
D & Steer & 8 & Potenza \\
E & Cow & 21 & Salerno \\
F & Cow & 11 & Potenza \\
G & Cow & 11 & Potenza \\
H & Cow & 8 & Salerno \\
I & Cow & 5 & Caserta \\
L & Steer & 5 & Salerno \\
M & Cow & 9 & Salerno \\
N & Cow & 8 & Salerno \\
O & Cow & 9 & Salerno \\
P & Cow & 16 & Salerno \\
\hline
\end{tabular}

media, SSIM [12] and SSIM1 (20 g/L glucose, $5 \mathrm{~g} / \mathrm{L}$ peptone, $5 \mathrm{~g} / \mathrm{L}$ yeast extract, $2 \mathrm{~g} / \mathrm{L} \mathrm{NaCl}, 0.4 \mathrm{~g} / \mathrm{L} \mathrm{NaHCO} 3,0.25 \mathrm{~g} / \mathrm{L}$ cysteine-HCl, $100 \mathrm{mg} / \mathrm{L}$ bacitracin, $1 \mathrm{mg} / \mathrm{L}$ lincomycin, $50 \mathrm{mg} / \mathrm{L}$ nystatin, $2.5 \mathrm{mg} / \mathrm{L}$ bromocresol purple, $12 \mathrm{~g} / \mathrm{L}$ bacteriological agar, $\mathrm{pH}$ 6.5). Concurrently, $100 \mu \mathrm{L}$ of each LB dilution was spread on Pasteurellaceae selective medium (PSM) [13] containing (per liter) $25 \mathrm{~g}$ of brain heart infusion, $50 \mathrm{~mL}$ of defibrinated sheep blood, $3.5 \mathrm{~mL}$ of $\beta$-nicotinamide adenine dinucleotide ( $\beta$-NAD), $100 \mathrm{mg}$ of bacitracin, $1 \mathrm{mg}$ of lincomycin, $50 \mathrm{mg}$ of nystatin, $100 \mathrm{mg}$ of crystal violet, and $18 \mathrm{~g}$ of bacteriological agar. The plates were incubated at $37^{\circ} \mathrm{C}$ for $18 \mathrm{~h}$ in an atmosphere with $5 \% \mathrm{CO}_{2}\left(\mathrm{CO}_{2}\right.$ incubator NOVACELL CO 170).

After incubation, single colonies were randomly isolated on the basis of their colony morphology (i.e., shape, edge, color, elevation, and dimension) by repetitive streaking on the same isolation media and were characterized on the basis of their microscopic morphology (phase-contrast microscopy, shape, and presence of spores) and biochemical features (Gram stains and catalase activity).

Representative isolates of each group were then identified by $16 \mathrm{~S}$ ribosomal RNA (rRNA) gene sequencing. Total DNA from the bacterial strains was extracted using InstaGene ${ }^{\mathrm{TM}}$ Matrix (Bio-Rad Laboratories, Hercules, CA, USA) according to the manufacturer's instructions. DNA (approximately $50 \mathrm{ng}$ ) was amplified with the primers FD1 (5'-AGA GTT TGA TCC TGG CTC AG-3') and RD1 (5'-AAG GAG GTG ATC CAG CC-3') using a PCR mixture employed as previously described [14]. The PCR conditions were as described by Giacobbe et al. [15]. Amplicons were purified using a QIAquick Gel Extraction kit (Qiagen S.p.A., Milan, Italy), and eluted DNAs were quantified and sequenced as previously reported [16]. Finally, nucleotide sequences were compared to the GenBank nucleotide data library using the 
BLAST software at the National Center of Biotechnology Information website (http://www.ncbi.nlm.nih.gov/Blast.cgi).

\section{Phylogenetic Analysis}

The nearly full-length 16S rRNA sequences of bacterial strains BPP7 and BPP8 and type strains belonging to different genera as described by Kuhnert et al. [13] were used to perform multiple nucleotide alignments using the ClustalW program [17] from MEGA version 4.0 [18]. The nucleotide sequences of the type strains were retrieved from the Ribosomal Database Project (RDP-http://rdPcme.msu.edu/). The phylogenetic tree was inferred using the Neighbor-Joining method with the Maximum Composite Likelihood model in the MEGA4 program, with bootstrap values based on 1000 replications.

\section{PCR-DGGE Analysis}

The total microbial DNA from enriched cultures was extracted using a FastDNA SPIN Kit for Soil (MP Biomedicals, Illkirch Cedex, France) according to the manufacturer's instructions. Primers V3f (5'-CCTACGGGAGGCAGCAG-3') and V3r (5'-ATTACCGCGGCTGCTGG-3') were employed to amplify the V3 hypervariable region of the $16 \mathrm{~S}$ rRNA gene (200 bp) using a previously described PCR mixture and conditions $[19,20]$. The amplicons were analyzed by denaturing gradient gel electrophoresis (DGGE) in a $0.8-\mathrm{mm}$ polyacrylamide gel using a Bio-Rad DCode Universal Mutation System (Bio-Rad, Laboratories, Milan, Italy) as described by Ventorino et al. [21]. After staining the gels for $30 \mathrm{~min}$ with SYBR Gold, image analysis of DGGE profiles was performed in Phoretix 1D Pro Gel Analysis Software (TotalLab Ltd., Newcastle, UK). Similarity analysis was performed as described by Marileo et al. [22] with a Bray-Curtis similarity index (5\% significance level) and was visualized by nonmetric multidimensional scaling (NMDS) using the software PRIMER-E version 6.1.

\section{SA Production by Pretreated Lignocellulosic Biomass}

A. donax biomass, pretreated according to Garbero et al. [23] and De Bari et al. [24], was utilized as substrate in separate hydrolysis and fermentation (SHF). Hydrolysis was performed by suspending $20 \mathrm{~g}$ of pretreated biomass in $100 \mathrm{~mL}$ of sodium acetate buffer $(0.05 \mathrm{M}, \mathrm{pH} 5.0)$ and adding the commercial cellulase mixture Cellic $\AA$ C Tec2, kindly provided by Novozymes (Bagsvaerd, Denmark), with a concentration of $70 \mathrm{FPU} / \mathrm{g}$ of pretreated biomass solids. The filter paper cellulase units (FPUs) of the enzyme Cellic ${ }^{\circledR}$ CTec2 were determined according to the standard procedure recommended by the International Union of Pure and Applied Chemistry (IUPAC) [25]. Hydrolysis was performed at $37{ }^{\circ} \mathrm{C}$ with shaking (120 rpm) for $72 \mathrm{~h}$. Samples were withdrawn after $72 \mathrm{~h}$ of the saccharification process, and glucose and xylose release was quantified by high-performance liquid chromatography (HPLC, refractive index detector 133; Gilson system; pump 307, column Metacarb $67 \mathrm{~h}$ (Varian) with flow $0.4 \mathrm{~mL} /$ $\min$ of $\mathrm{H}_{2} \mathrm{SO}_{4} 0.01 \mathrm{~N}$ ).

The fermentation step was performed using either the pretreated biomass directly after hydrolysis including solid and liquid fractions (PB) or the clarified hydrolysate including only the liquid fraction that was recovered with a peristaltic pump after $3 \mathrm{~h}$ of sedimentation under gravity and drawn (PBS). One hundred milliliters each of PB and PBS was supplemented with $\mathrm{MH}$ components $(10 \mathrm{~g} / \mathrm{L}$ polypeptone, $5 \mathrm{~g} / \mathrm{L}$ yeast extract, $3 \mathrm{~g} / \mathrm{L} \mathrm{K}{ }_{2} \mathrm{HPO}, 2 \mathrm{~g} / \mathrm{L} \mathrm{NaCl}, 2 \mathrm{~g} / \mathrm{L}\left(\mathrm{NH}_{4}\right) \mathrm{SO}_{4}$, $0.2 \mathrm{~g} / \mathrm{L} \mathrm{CaCl} 2,0.2 \mathrm{~g} / \mathrm{L} \mathrm{MgCl} 2,10 \mathrm{~g} / \mathrm{L} \mathrm{MgCO}_{3}, 0.001 \mathrm{~g} / \mathrm{L}$ $\mathrm{Na}_{2} \mathrm{~S}, \mathrm{pH}$ 6.5) [3], reaching glucose and xylose concentrations of approximately $12 \mathrm{~g} / \mathrm{L}$ each. The two obtained media, PBMH and PBSMH, were autoclaved at $120^{\circ} \mathrm{C}$ for $15 \mathrm{~min}$ and were inoculated with the two selected strains, $B$. succiniciproducens BPP7 and B. succiniciproducens BPP8, to reach a microbial concentration of approximately $2 \times 10^{7}$ cells $/ \mathrm{mL}$. Triplicate fermentation experiments were conducted under static anaerobic conditions at $37{ }^{\circ} \mathrm{C}$ (Whitley DG250 Anaerobic Workstation, Don Whitley Scientific, Shipley, England). SA production and glucose and xylose consumption were measured by HPLC at $0,24,48$, and $72 \mathrm{~h}$. SA yield was defined as grams of SA per gram of consumed glucose and xylose $\left(\mathrm{Y}_{\mathrm{SA} / \mathrm{G}+\mathrm{X}}, \mathrm{g} / \mathrm{g}\right)$ and as grams of SA per gram of total sugars (glucans and xylans) present in the A. donax biomass before hydrolysis $\left(\mathrm{Y}_{\mathrm{SA} / \mathrm{PB}}, \mathrm{g} / \mathrm{g}\right)$.

During the SHF process, the growth of the bacterial strains was also determined by spreading tenfold serial dilutions on Brain-Heart Infusion medium (BHI, Oxoid, Milan, Italy). The plates were incubated for $24 \mathrm{~h}$ at $37^{\circ} \mathrm{C}$ in an atmosphere with $5 \% \mathrm{CO}_{2}\left(\mathrm{CO}_{2}\right.$ incubator NOVACELL CO 170).

\section{Optimization and Scale-up of SA Production in Shake Flasks and 2.5-L Batch Experiments}

Optimization of SA production was performed for B. succiniciproducens BPP7, which was identified as the best candidate in previous experiments. All cultivations were conducted in $250-\mathrm{mL}$ bottles with $250 \mathrm{~mL}$ of medium at $37{ }^{\circ} \mathrm{C}$ and shaking at $140 \mathrm{rpm}$, if necessary, in a rotary shaker incubator (Minitron, Infors, Bottmingen, Switzerland). The bottles were sealed with stainless steel headpiece caps and sterile venting filters to insufflate $\mathrm{CO}_{2}$, if necessary, before starting the experiment. Experiments were either conducted on standard $\mathrm{MH}$ medium or on a modified medium containing $\mathrm{MH}$ salts, supplemented with yeast extract $(5,1$, or $0 \mathrm{~g} / \mathrm{L})$ and polypeptone $(15,10$ or $0 \mathrm{~g} / \mathrm{L})$ and in which glucose was replaced by A. donax hydrolysate. A. donax hydrolysate was diluted to achieve the desired starting concentration of sugars. 
Glucose or A. donax hydrolysate was autoclaved separately and added to the medium before strain inoculation. The medium $\mathrm{pH}$ was adjusted to 6.5 .

Cell growth was monitored by removing $\mathrm{MgCO}_{3}$ from the broth according to Becker et al. [26] to avoid interference of this insoluble compound with biomass quantification. Samples were withdrawn during the course of the experiment to analyze glucose and xylose (if present) consumption and organic acid production. Every experiment was repeated at least three times.

For fermentation experiments, seed cultures were inoculated with the working cell bank and grown in $250-\mathrm{mL}$ bottles as described in the previous section for $16 \pm 1 \mathrm{~h}$ on $\mathrm{MH}$ medium with glucose as a $\mathrm{C}$ source and yeast extract as a complex nitrogen source. The main cultures were grown on a Biostat CT (Sartorius Stedim; Melsungen, Germany) filled with a final volume of $2.5 \mathrm{~L}$ of broth composed by $\mathrm{MH}$ components, yeast extract as a complex nitrogen source, and $A$. donax hydrolysate as carbon source (starting glucose concentration of 4.3 or $8.0 \mathrm{~g} /$ $\mathrm{L}$ and starting xylose concentration of 2.5 or $4.7 \mathrm{~g} / \mathrm{L}$ for experiment 1 and experiment 2, respectively). All experiments were conducted at $37{ }^{\circ} \mathrm{C}$ with $\mathrm{CO}_{2}$ sparging at $0.5 \mathrm{vvm}$ and an agitation speed set to $100 \mathrm{rpm}$. A constant $\mathrm{pH}$ of 6.5 was maintained via automated addition of $\mathrm{NH}_{4} \mathrm{OH}$ (Sigma-Aldrich).

Broth samples were collected every $2 \mathrm{~h}$ during cultivation to follow biomass formation (when possible), substrate consumption, and product formation. The supernatants obtained after centrifugation at $5000 \times g$ were ultrafiltered on $3-\mathrm{kDa}$ Centricon devices (Millipore, Bedford, MA, USA), and the flowthrough was analyzed by HPLC in an UltiMate 3000 on an Alltech IOA-2000 column ( $500 \mathrm{~mm} \times 6.5 \mathrm{~mm} \mathrm{ID})$ at $40^{\circ} \mathrm{C}$ with $0.1 \% v / v$ phosphoric acid in water as the mobile phase at a flow rate of $0.6 \mathrm{~mL} / \mathrm{min}$. Detection was performed via UV absorbance at $200 \mathrm{~nm}$ and refraction index (Shodex RI-101 detector, max auto step $5.1 \mathrm{~s}$, temperature $32^{\circ} \mathrm{C}$, rise time $1 \mathrm{~s}$, polarity plus, record range $512 \mu \mathrm{RIU}$, integrator range $500 \mu \mathrm{RIU} / \mathrm{UV})$.

\section{Statistical Analyses}

One-way ANOVA followed by Duncan's post hoc test for pairwise comparison of means (at $p \leq 0.05$ ) was used to assess the difference in the SA production on different fermentation media. Statistical analyses were performed using the SPSS 21.0 statistical software package (SPSS Inc., Cary, NC, USA) [27].

\section{Nucleotide Sequence Accession Numbers}

The 16S rRNA gene sequences obtained from the bacterial strains were deposited in the GenBank database under accession numbers KT362365 and KT362366 for the strains BPP7 and BPP8, respectively, and from KX156160 to KX156256 for the other strains.

\section{Results and Discussion}

\section{Microbial Diversity and Isolation of Putative SA-Producing Bacteria}

Bacterial diversity of the enriched cultures was evaluated using a culture-independent approach with PCR-DGGE to detect changes of complex bacterial communities in the environment based on different profiles obtained by base-pair sequences of amplicons with the same length [28]. This methodology demonstrated a high biodiversity among samples, with similarity levels from 35 to $90 \%$ (Fig. 1a). The DGGE profiles obtained were used to evaluate the levels of similarity of the bacterial community between the different rumen samples by cluster analysis. As shown in Fig. 1b, the samples could be grouped into seven major clusters. One group included five rumen samples (F, G, N, O, and P), whereas the other six groups consisted of two (cluster 2: D and M; cluster 3: $\mathrm{C}$ and L; cluster 4: I and B) or one (cluster 5: A; cluster 6: E; cluster 7: H) rumen sample (Fig. 1b). Interestingly, the diversity of bacterial populations investigated using this cultureindependent approach highlighted that it did not seem to be influenced by the features of the samples, such as breed, age, and geographical origin, described in Table 1. In fact, the cluster 1 grouped samples originated from cows aged from 8 to 16 years that were bred in Potenza (Basilicata region, Italy) and Salerno (Campania region, Italy), and the cluster 2 grouped samples originated from cows and steers bred in Potenza and Salerno. Similar results were also shown for samples grouped in the other clusters.

The bacterial diversity of the enriched cultures was also evaluated using a culture-dependent approach to isolate and select SA-producing microorganisms. The selective culturedependent approach used in this work enabled for the isolation of facultative anaerobic and/or microaerophilic bacteria from rumen samples characterized by the presence of fermentative microorganisms and, in particular, potential SA-producing microbes. In fact, the two ionoporic antibiotics, lasalocid and monensin, that were added to the media inhibited acetic acid-producing and hydrogen-producing microorganisms, usually present in the rumen, and favored the growth of SAand propionic acid-producing bacteria [29]. A total of 364 potential SA-producing bacteria were isolated and grouped on the basis of their colony and microscopic morphologies and on their biochemical features (data not shown). Among these bacteria, 99 representative strains were selected and identified by $16 \mathrm{~S}$ rRNA gene sequencing. The molecular identification resulted in bacterial isolates with great biodiversity, as 21 genera and 37 different species were found (Fig. 2).

Enterobacteriales was the most represented order $(48.5 \%)$, consisting of the genera Proteus spp. (33.33\%), Providencia spp. (5.05\%), Raoultella spp. (4.04\%), Pantoea spp. (1.01\%), Citrobacter spp. (1.01\%), Klebsiella spp. (1.01\%), Serratia 
Fig. 1 DGGE profiles and cluster analysis (a) and non-metric multidimensional scaling analysis (NMDS) of DGGE profiles (b) of the bacterial communities in the enriched cultures
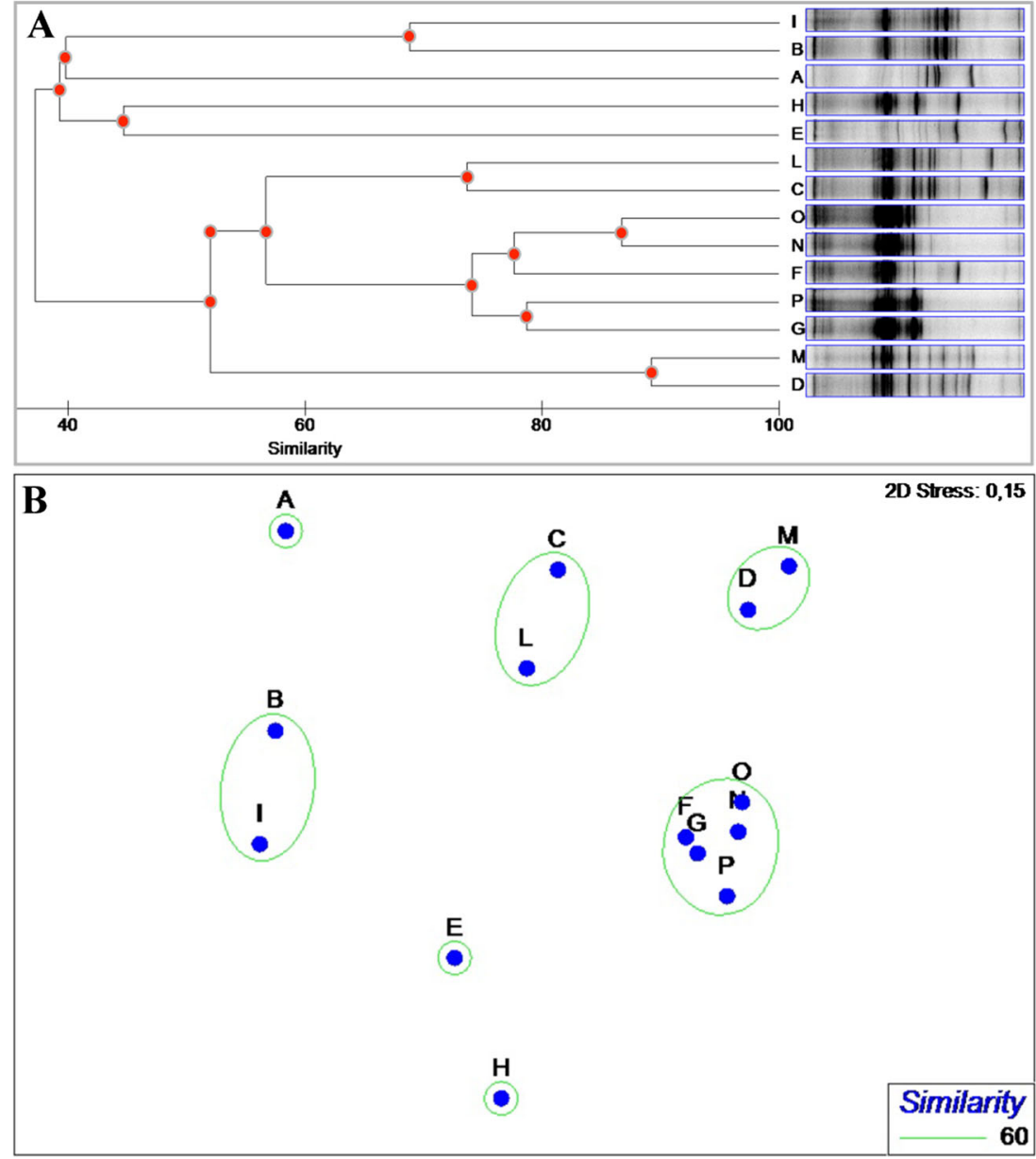

spp. (1.01\%), Hafnia spp. (1.01\%), and Obesumbacterium spp. (1.01\%). Bacteria belonging to the genera Proteus spp., Raoultella spp., Citrobacter spp., and Klebsiella spp. were recovered in the ruminal fluid of dairy cattle, rumen samples, and bovine fecal material [30-32]; their occurrence in ruminants could be expected because some of these genera, such as Pantoea, Raoultella, and Citrobacter, are reported to be cellulase-producing bacteria [10, 33]. Moreover, according to Mao et al. [34], in addition to Proteobacteria, Firmicutes is a predominant phylum found in rumen samples of dairy cattle. In fact, in this study, Bacillales and Lactobacillales, covering 28.3 and $18.2 \%$ of bacterial biodiversity, respectively, were the other orders recovered at high incidence, although their occurrence depended on cattle sample types. Lactobacillales, strongly dominated by Enterococcus spp. (8.08\%), followed by Weissella $(5.05 \%)$, Lactococcus (3.03\%), Lactobacillus (1.01\%), and Streptococcus (1.01\%), were mainly isolated from samples L and P. By contrast, Bacillales were isolated from all samples except for the $\mathrm{L}$ and $\mathrm{M}$ samples. Bacteria belonging to the genus Bacillus covered $23.23 \%$ of the isolated strains (Fig. 2). This ubiquitous genus includes different cellulolytic bacteria exhibiting interesting enzymatic activities for the hydrolysis of lignocellulosic biomass carbohydrates into fermentable sugars for a wide range of industrial applications [35-37].

Finally, to a lesser extent, bacteria belonging to Acinetobacter spp. (2.0\%), Basfia spp. (2.0\%), and Comamonas spp. (1.0\%) were also recovered (Fig. 2). Among all isolates, the two new strains, B. succiniciproducens BPP7 and B. succiniciproducens BPP8, were the most promising microorganisms, as the bacteria belonging to this species have been reported to be efficient producers of SA [13]. Therefore, to confirm the molecular identification of these bacterial strains, a phylogenetic tree was constructed. The results of the Neighbor-Joining analysis of the $16 \mathrm{~S}$ rRNA sequences of the bacterial strains are shown in the dendrogram depicted in Fig. 3. The closest relative species was B. succiniciproducens, demonstrating that strains BPP7 and BPP8 could be ascribed to this species.

\section{SA Production and Optimization}

The preliminary fermentation screening of 20 representative strains in $100 \mathrm{~mL}$ of MH-rich medium supplemented with $20 \mathrm{~g} / \mathrm{L}$ glucose was performed to select the best SAproducing bacteria. Among all tested strains, chosen on the basis of molecular identification and incidence percentage, 

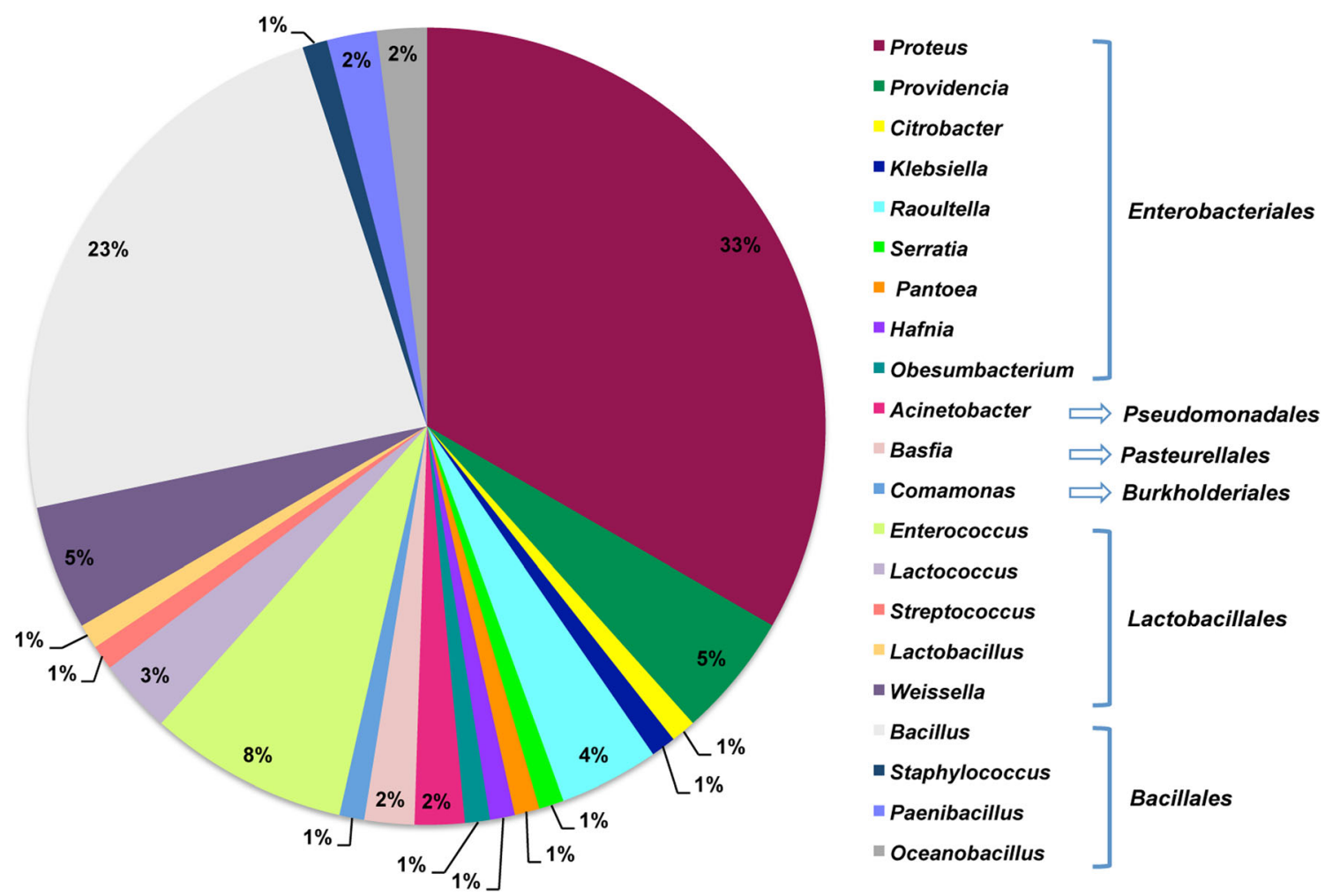

Fig. 2 Percentage compositions of different genera of bacterial strains isolated from enriched cultures on the basis of 16S rRNA gene sequence similarity

only B. succiniciproducens BPP7 and B. succiniciproducens BPP8 were able to secrete large amounts of succinate (data not shown).

On the basis of the preliminary results, these two strains were selected and evaluated for their capacity to synthesize succinate from pretreated lignocellulosic biomass of $A$. donax in SHF using either the pretreated biomass directly after hydrolysis (PB) or the liquid fraction (PBS). Due to its high carbohydrate contents and capacity to grow in marginal and contaminated lands not suitable for food crops [38], the lignocellulosic biomass of $A$. donax is an interesting substrate for bioconversion to SA. Moreover, although different waste and lignocellulosic materials, such as corncobs, corn stover, rapeseed, rice, wheat straw, switchgrass, bagasse, and oak wood $[1,39]$, have been employed to produce bio-based chemicals, the use of $A$. donax hydrolysate as a substrate for SA production was first reported only recently [12].

In SHF experiments, the two new bacterial strains were able to synthesize high levels of succinate in all tested conditions. In particular, the concentration of SA recovered from strain B. succiniciproducens BPP7 was notable after $24 \mathrm{~h}$ (glucose and xylose consumption of approximately $45 \%$ ), increasing up to $4.38 \pm 0.09 \mathrm{~g} / \mathrm{L}\left(\mathrm{Y}_{\mathrm{SA} / \mathrm{G}+\mathrm{X}}\right.$ of $0.39 \pm 0.010 \mathrm{~g} / \mathrm{g}$ and $\mathrm{Y}_{\mathrm{SA} / \mathrm{PB}}$ of $\left.0.10 \pm 0.002 \mathrm{~g} / \mathrm{g}\right)$ and $6.06 \pm 0.05 \mathrm{~g} / \mathrm{L}\left(\mathrm{Y}_{\mathrm{SA} / \mathrm{G}+\mathrm{X}}\right.$ of $0.84 \pm 0.017 \mathrm{~g} / \mathrm{g}$ and $\mathrm{Y}_{\mathrm{SA} / \mathrm{PB}}$ of $0.14 \pm 0.001 \mathrm{~g} / \mathrm{g}$ ) after $48 \mathrm{~h}$ using PBMH and PBSMH, respectively (Table 2). However, in PBMH, there were no significant differences $(p>0.05)$ among the three sampling times $(24,48$, and $72 \mathrm{~h})$, whereas in the PBSMH substrate, the SA production significantly decreased after $72 \mathrm{~h}$ (Table 2). These results emphasized that the use of $A$. donax hydrolysate recovered by sedimentation under the gravity method promoted the fermentation activity of the strain B. succiniciproducens BPP7, showing the highest succinate production and yield. This result could be due to the presence of specific toxic compounds (e.g., furfural, HMF, phydroxybenzoic aldehyde, and vaniline) in solid components of the pretreated biomass hydrolysate used in the PBMH medium. These compounds are known to have an inhibitory effect on microbial metabolism, limiting the efficiency of conversion of fermentable sugars in biochemicals and biofuels [40].

Similar results were obtained using the strain B. succiniciproducens BPP8. In fact, after $24 \mathrm{~h}$, most of the glucose and xylose consumption (approximately 50\%) and notable synthesis of succinate were recorded (Table 2). In PBMH and PBSMH conditions, after $48 \mathrm{~h}$ of fermentation, the SA production significantly increased up to $4.03 \pm 0.07 \mathrm{~g} /$ $\mathrm{L}\left(\mathrm{Y}_{\mathrm{SA} / \mathrm{G}+\mathrm{X}}\right.$ of $0.34 \pm 0.009 \mathrm{~g} / \mathrm{g}$ and $\mathrm{Y}_{\mathrm{SA} / \mathrm{PB}}$ of $0.09 \pm 0.002 \mathrm{~g} /$ $\mathrm{g})$ and $5.37 \pm 0.06 \mathrm{~g} / \mathrm{L}\left(\mathrm{Y}_{\mathrm{SA} / \mathrm{G}+\mathrm{X}}\right.$ of $0.84 \pm 0.020 \mathrm{~g} / \mathrm{g}$ and $\mathrm{Y}_{\mathrm{SA} /}$ $\mathrm{PB}$ of $0.12 \pm 0.001 \mathrm{~g} / \mathrm{g}$ ), respectively (Table 2), emphasizing that this strain also exhibited the highest succinate amount and yield in the PBSMH condition. Nevertheless, in both tested 
Fig. 3 Neighbor-Joining tree based on the comparison of $16 \mathrm{~S}$ rRNA gene sequences showing the phylogenetic relationships among strains BBP7 and BPP8 isolated in this study and type strains. Bootstrap values (expressed as percentages of 1000 replications) are given at the nodes. The sequence accession numbers used for the phylogenetic analysis are shown in parentheses following the species names. Strains marked with "(T)" represent type strains. The scale bar estimates the number of substitutions per site

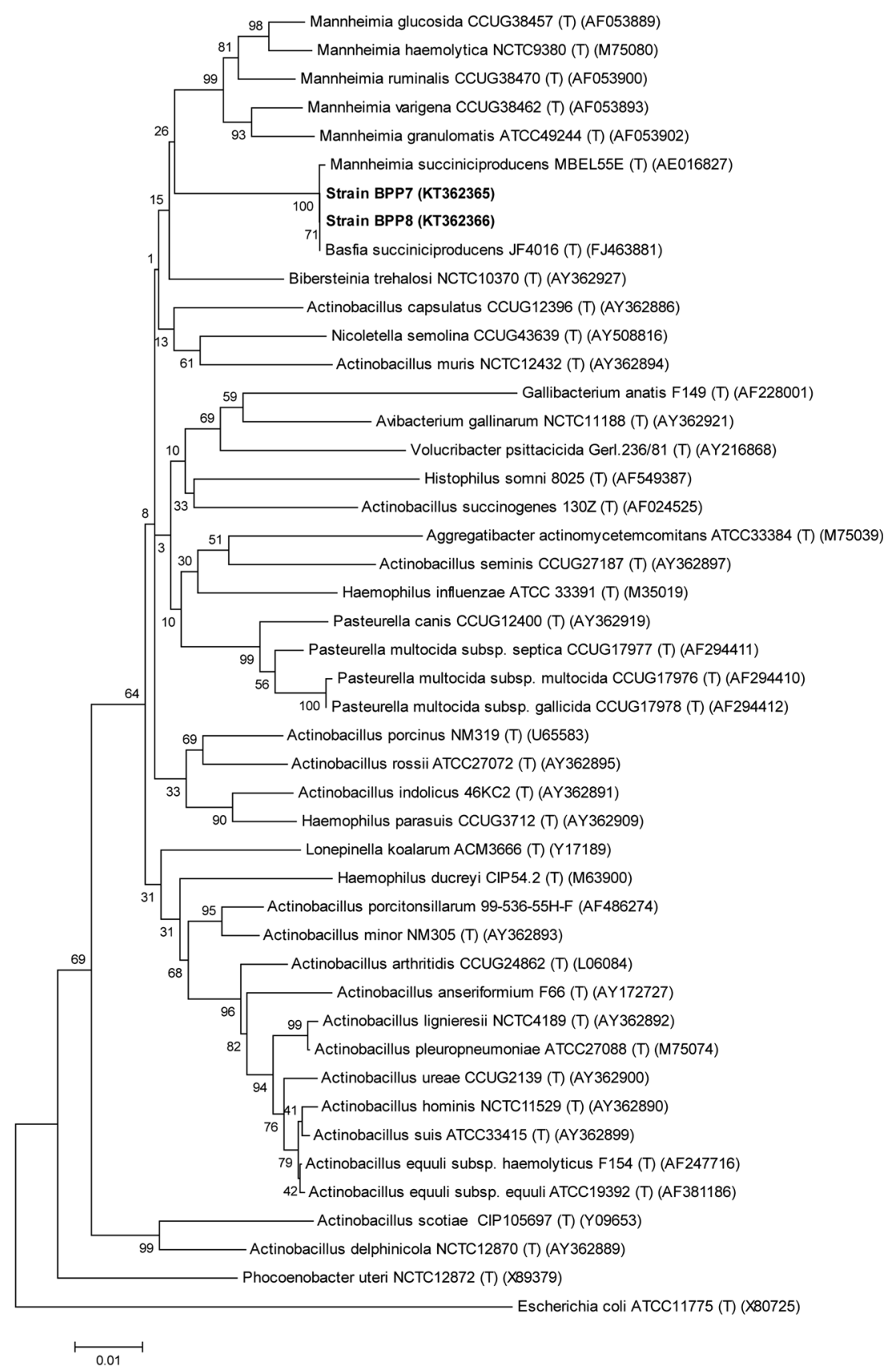

conditions, either the succinate concentration decreased or no significant differences were observed after $72 \mathrm{~h}$.

However, the SA production capacity of strain B. succiniciproducens BPP7 was higher than that of B. succiniciproducens BPP8 on both PBSMH $(+12.85 \%)$ and PBMH $(+8.68 \%)$ after $48 \mathrm{~h}$. Moreover, considering the highest SA synthesis of the strain $B$. succiniciproducens BPP7, the mass balance from $1 \mathrm{~kg}$ of pretreated $A$. donax biomass (containing $0.1 \mathrm{~kg}$ of glucans and xylans) was $0.014 \mathrm{~kg}$ of SA. Therefore, on the basis of these results, additional experiments in larger bottles were performed to further optimize the production of SA from B. succiniciproducens
BPP7. The effects of agitation and $\mathrm{CO}_{2}$ sparging on biomass and SA production to identify the best operating conditions were initially investigated. These preliminary assays were performed on $\mathrm{MH}$-rich medium containing glucose as a $\mathrm{C}$ source to avoid interference due to other factors linked to the presence of a complex substrate such as A. donax hydrolysate. As shown in Table 3 , after $24 \mathrm{~h}$ of growth, more SA was produced in the agitated cultures and a further slight improvement was obtained by creating an anaerobic environment with $\mathrm{CO}_{2}$ sparging, resulting in $0.75 \mathrm{~g}$ of SA per gram of glucose and a final titer of approximately $8 \mathrm{~g} / \mathrm{L}$ of the target molecule. In all setups, glucose was never exhausted from the medium 
Table 3 Production of biomass, succinic acid (SA), and acetic acid of strain B. succiniciproducens BPP7 on MH standard medium containing $20 \mathrm{~g} / \mathrm{L}$ glucose in batch cultivations conducted in bottles for $24 \mathrm{~h}$

\begin{tabular}{lllll}
\hline Conditions & $\mathrm{SA}(\mathrm{g} / \mathrm{L})$ & $\mathrm{OD}_{600}$ & Acetic acid $(\mathrm{g} / \mathrm{L})$ & $\mathrm{Y}_{\mathrm{SA} / \mathrm{G}}(\mathrm{g} / \mathrm{g})$ \\
\hline $\mathrm{S}_{24 \mathrm{~h}}$ & $4.40 \pm 0.87$ & $3.88 \pm 0.12$ & $2.91 \pm 0.16$ & $0.59 \pm 0.06$ \\
$\mathrm{~S}+\mathrm{CO}_{2} 24 \mathrm{~h}$ & $6.37 \pm 0.62$ & $3.67 \pm 0.12$ & $3.17 \pm 0.11$ & $1.11 \pm 0.12$ \\
$\mathrm{~A}_{24 \mathrm{~h}}$ & $7.92 \pm 1.18$ & $6.80 \pm 1.19$ & $3.32 \pm 1.69$ & $0.67 \pm 0.05$ \\
$\mathrm{~A}+\mathrm{CO}_{2} 24 \mathrm{~h}$ & $8.21 \pm 0.35$ & $6.35 \pm 0.52$ & $4.59 \pm 0.24$ & $0.75 \pm 0.10$
\end{tabular}

$S$ static, $A$ agitation, $\mathrm{CO}_{2}$ initial sparging with $\mathrm{CO}_{2}$ to create an anaerobic environment, $Y_{S A / G}$ grams of succinate produced per gram of consumed glucose

during the $24 \mathrm{~h}$ of growth, and the major by-product was acetate (Table 3). The results obtained in this work highlight that the selected wild-type strain B. succiniciproducens BPP7 could be considered a natural high SA producer due to its SA yield $(0.75 \mathrm{~g} / \mathrm{g})$, as it showed similar or higher SA levels compared with those produced by other wild-type B. succiniciproducens strains. In fact, the new natural strain BPP7 synthesized up to $8 \mathrm{~g} / \mathrm{L}$, with a yield of $0.75 \mathrm{~g} / \mathrm{g}$ of SA, starting from the synthetic substrate MH containing $20 \mathrm{~g} / \mathrm{L}$ of glucose, whereas the capacities of different wild-type strains of $B$. succiniciproducens that produced approximately $5 \mathrm{~g} / \mathrm{L}$ from a synthetic substrate (BHI) with $20 \mathrm{~g} / \mathrm{L}$ of glucose were described by Kuhnert et al. [13]. Similarly, Becker et al. [26] reported the natural capacity of the wild-type strain B. succiniciproducens DD1 to synthesize SA with a metabolic yield of $0.49 \mathrm{~g} / \mathrm{g}$, starting from $45 \mathrm{~g} / \mathrm{L}$ of glucose. However, the biotechnological performance of $B$. succiniciproducens BPP7 is also comparable to that obtained in other studies using genetically modified strains of $B$. succiniciproducens in synthetic media with glucose as the carbon source. Becker et al. [26] significantly improved $\mathrm{Y}_{\mathrm{SA} / \mathrm{G}}$ up to $0.71 \mathrm{~g} / \mathrm{g}$ by engineering $B$. succiniciproducens DD1 by the double deletion of pyruvate formate lyase ( $p f l D$ ) and lactate dehydrogenase $(l d h A)$. Production of succinate by the mutant LU15224 pJFF224 (icl ms Y.m.), obtained from B. succiniciproducens DD1 engineered by the double knockout of $\Delta l d h$ and $\Delta p f l D$, which over-expresses the plasmid pJFF224 (icl ms Y.m.) and contains the glyoxylate shunt operon genes of Yersinia molaretii, resulted in a yield of $0.87 \mathrm{~g} / \mathrm{g}$ [41].

A second set of experiments was performed on $\mathrm{MH}$ medium supplemented with $A$. donax hydrolysate directly recovered after sedimentation (PBSMH) with the aim to simplify medium composition. Soy peptone was revealed to be unnecessary whereas the addition of yeast extract to the hydrolysate resulted in the highest final titer of SA, approximately $6 \mathrm{~g} / \mathrm{L}$ after $24 \mathrm{~h}$ (Table 4). This corresponded to a $\mathrm{Y}_{\mathrm{SA} / \mathrm{G}+\mathrm{X}}$ of $1.08 \pm 0.27 \mathrm{~g} / \mathrm{g}$, almost threefold higher compared to that obtained in the control experiment, and to a $\mathrm{Y}_{\mathrm{SA} / \mathrm{PB}}$ of $0.64 \pm 0.06 \mathrm{~g} / \mathrm{g}$. In addition, a 100\% increased productivity 
Table 4 Production of succinic acid (SA) of the strain

B. succiniciproducens $\mathrm{BPP} 7$ in 250-mL bottle experiments using A. donax hydrolysate in the PBSMH condition. Different concentrations and ratios of soy peptone and yeast extract were evaluated

\begin{tabular}{lllllll}
\hline $\begin{array}{l}\text { Soy peptone } \\
(\mathrm{g} / \mathrm{L})\end{array}$ & $\begin{array}{l}\text { Yeast extract } \\
(\mathrm{g} / \mathrm{L})\end{array}$ & SA $(\mathrm{g} / \mathrm{L})$ & $\begin{array}{l}\text { Acetic acid } \\
(\mathrm{g} / \mathrm{L})\end{array}$ & $\begin{array}{l}\text { Ethanol } \\
(\mathrm{g} / \mathrm{L})\end{array}$ & $\begin{array}{l}\mathrm{Y}_{\mathrm{SA} / \mathrm{G}+\mathrm{X}} \\
(\mathrm{g} / \mathrm{g})\end{array}$ & $\begin{array}{l}\mathrm{Y}_{\mathrm{SA} / \mathrm{PB}} \\
(\mathrm{g} / \mathrm{g})\end{array}$ \\
\hline 10 & 5 & $4.20 \pm 0.73$ & $3.10 \pm 0.20$ & $1.87 \pm 0.43$ & $0.39 \pm 0.09$ & $0.23 \pm 0.03$ \\
15 & 1 & $5.47 \pm 0.30$ & $1.86 \pm 0.40$ & $0.89 \pm 0.12$ & $0.66 \pm 0.04$ & $0.06 \pm 0.00$ \\
0 & 5 & $6.00 \pm 0.89$ & $1.38 \pm 0.28$ & $0.19 \pm 0.02$ & $1.08 \pm 0.27$ & $0.64 \pm 0.06$ \\
0 & 0 & $2.60 \pm 0.80$ & $1.45 \pm 0.35$ & $1.25 \pm 0.10$ & $0.22 \pm 0.10$ & $0.14 \pm 0.04$ \\
\hline
\end{tabular}

The cultivations were performed in batch conditions for $24 \mathrm{~h}$ at $37^{\circ} \mathrm{C}$ with initial sparging of $\mathrm{CO}_{2}$ and agitation. $\mathrm{Y}_{\mathrm{SA} / \mathrm{G}+\mathrm{X}}$ indicates grams of succinic acid produced per gram of glucose and xylose consumed. $\mathrm{Y}_{\mathrm{SA} / \mathrm{PB}}$ indicates grams of succinic acid on grams of glucans and xylan present in A.donax before hydrolysis
$\left(\mathrm{Y}_{\mathrm{SA} / \mathrm{L} \cdot \mathrm{h}}\right)$ was obtained compared with values observed in 100-mL SHF experiments on A. donax hydrolysate recovered after sedimentation. Moreover, elimination of soy peptone also decreased the amount of ethanol produced by almost tenfold indicating a redistribution of carbon fluxes. Therefore, even though the complex nitrogen sources were reduced (i.e., no polypeptone), improved process characteristics were successfully demonstrated. However, acetic acid remained the major by-product in all media tested.

On the basis of these results, B. succiniciproducens BPP7 was finally analyzed in 2.5 -L batch experiments in the optimized cultivation conditions identified in previous bottle experiments (anaerobic conditions, only yeast extract as a complex nitrogen source). A. donax hydrolysate was diluted, and two experiments with increasing initial concentrations of glucose and xylose were performed. The experiments lasted $24 \mathrm{~h}$,

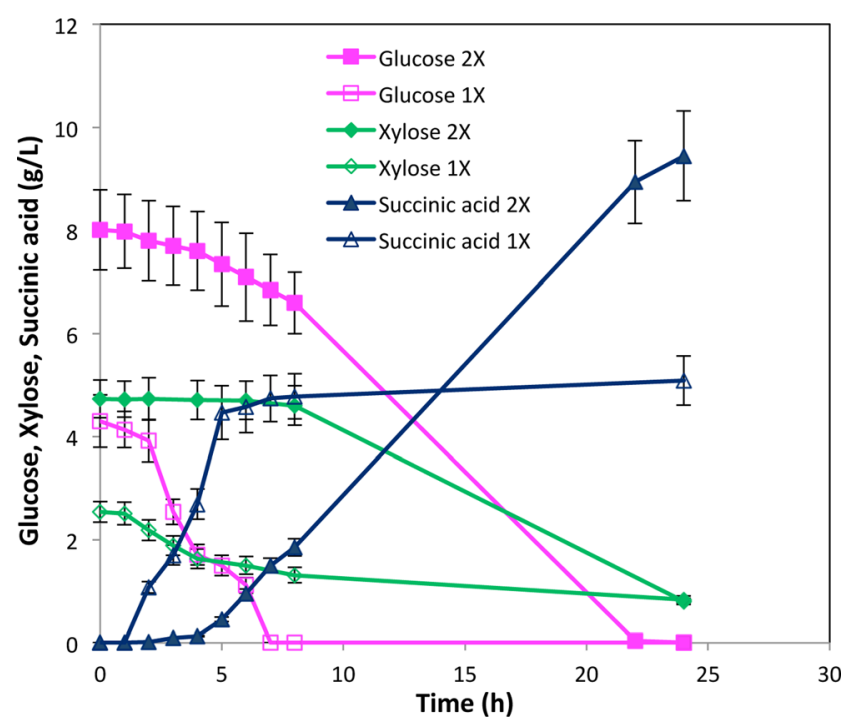

Fig. 4 B. succiniciproducens BPP7 grown in batch fermentation experiments with $A$. donax hydrolysate in PBSMH containing yeast extract as a complex nitrogen source with different initial concentrations of glucose and xylose. Experiments were conducted at $37{ }^{\circ} \mathrm{C}$ with continuous sparging of $\mathrm{CO}_{2}$ at $0.5 \mathrm{vvm}$. Starting concentrations of glucose in the medium are denoted as $2 \mathrm{X}$ for $8.0 \mathrm{~g} / \mathrm{L}$ and $1 \mathrm{X}$ for $4.3 \mathrm{~g} / \mathrm{L}$; starting concentrations of xylose in the medium are denoted as $2 \mathrm{X}$ for $4.7 \mathrm{~g} / \mathrm{L}$ and $1 \mathrm{X}$ for $2.5 \mathrm{~g} / \mathrm{L}$ and the final concentrations of SA were measured at approximately 5 and $9 \mathrm{~g} / \mathrm{L}$, respectively (Fig. 4). The yields of SA and acetic acid (the major organic acid by-products) on total consumed sugars (glucose and xylose) were consistent in the two batches and corresponded to $0.84 \pm 0.01$ and $0.30 \pm 0.04 \mathrm{~g} / \mathrm{g}$, respectively (Fig. 4). Therefore, process scalability was assessed, and batch experiments with higher initial sugar concentrations in the A. donax hydrolysate demonstrated the reproducibility of the $\mathrm{Y}_{\mathrm{SA} / \mathrm{G}+\mathrm{X}}$. The yield of succinic acid on the total polysaccharides (glucans and xylans) present in A. donax before hydrolysis was equal to $0.71 \pm 0.02 \mathrm{~g} / \mathrm{g}$, indicating a slight improvement compared to that obtained in bottle experiments in similar conditions. In addition, using the optimized cultivation conditions in 2.5-L batch experiments, the mass balance from $1 \mathrm{~kg}$ of pretreated $A$. donax biomass (containing $0.1 \mathrm{~kg}$ of glucans and xylans) was $0.072 \mathrm{~kg}$ of SA.

Overall, these results highlight the high biotechnological potential of the natural SA-producing selected wild-type strain B. succiniciproducens BPP7 to produce second-generation biochemicals. B. succiniciproducens is relatively unexplored if it is to be considered for its potential to synthesize SA from lignocellulosic biomass and, in particular, from $A$. donax hydrolysate. As reported above, few examples of wild-type and engineered B. succiniciproducens-producing high titers of SA are present in the literature, and most are based on fermentation processes that exploit refined carbon sources (i.e., purified sugars) [42]. Pateraki et al. [43] in fermentation experiments using a mixture of C5 and C6 sugars obtained a succinic acid yield (referring to grams of succinic acid produced per gram of total sugars consumed) up to 0.76 and $0.69 \mathrm{~g} / \mathrm{g}$ for B. succiniciproducens DSM 22022 and A. succinogenes DSM 22257 , respectively. Recently, the ability to synthetize succinic acid from spent sulfite liquor (aqueous waste stream containing solubilized lignin and sugars resulting from hemicellulose degradation) of the strains $B$. succiniciproducens DSM 22022 (yield from 0.45 to $0.58 \mathrm{~g}$ per gram of consumed sugars) was reported [44]. However, the challenge is to develop strategies that enable the exploitation of sugars contained in renewable resources that are not competing with foodborne sources. Only recently, the capacity of the wild-type strain B. succiniciproducens DSM 22022 to synthesize succinate 
from corn stover hydrolysate was first investigated [45]. However, Salvachúa et al. [45] reported that the maximum SA yield was $0.69 \mathrm{~g} / \mathrm{g}$ lignocellulosic hydrolysate at an initial sugar concentration of $60 \mathrm{~g} / \mathrm{L}$. This value is lower than that recovered in this study in the different fermentation conditions using A. donax hydrolysate at an initial sugar concentration from 12 to $24 \mathrm{~g} / \mathrm{L}\left(\mathrm{Y}_{\mathrm{SA} / \mathrm{G}+\mathrm{X}}\right.$ of $\left.0.84 \mathrm{~g} / \mathrm{g}\right)$.

\section{Conclusions}

In conclusion, the ecological strategy employed in this study enabled the isolation of new bacterial strains that are able to synthesize SA from renewable lignocellulosic biomass. The natural SA-producing selected wild-type strain B. succiniciproducens BPP7 demonstrated interesting biotechnological applications, as it efficiently fermented A. donax hydrolysate, thereby producing succinate. The yield obtained in small-scale shake flask experiments was confirmed in 2.5-L bioreactors on a simplified medium containing A. donax supplemented with yeast extract. Although process development is still necessary to reach industrially appealing titers, the results obtained thus far are promising.

Acknowledgments This study was supported by grant from the Ministero dell'Università e della Ricerca Scientifica Industrial Research Project "Development of green technologies for production of BIOchemicals and their use in preparation and industrial application of POLImeric materials from agricultural biomasses cultivated in a sustainable way in Campania region-BioPoliS" PON03PE_00107_1/1, funded in the frame of Operative National Programme Research and Competitiveness 2007-2013 D. D. Prot. n. 713/Ric. del 29.10.2010. We are grateful to Novozymes (Bagsvaerd, Denmark) for cellulase supply and to Dr. Giancarlo Trezza for his help with the sampling in slaughterhouses.

Open Access This article is distributed under the terms of the Creative Commons Attribution 4.0 International License (http:// creativecommons.org/licenses/by/4.0/), which permits unrestricted use, distribution, and reproduction in any medium, provided you give appropriate credit to the original author(s) and the source, provide a link to the Creative Commons license, and indicate if changes were made.

\section{References}

1. Akhtar J, Idris A, Aziz RA (2014) Recent advances in production of succinic acid from lignocellulosic biomass. Appl Microbiol Biotechnol 98:987-1000. doi:10.1007/s00253-013-5319-6

2. Isar J, Agarwal L, Saran S, Saxena RK (2006) A statistical method for enhancing the production of succinic acid from Escherichia coli under anaerobic conditions. Bioresour Technol 97:1443-1448. doi:10.1016/j.biortech.2005.07.014

3. Lee PC, Lee SY, Hong SH, Chang HN (2002) Isolation and characterization of new succinic acid producing bacterium, Mannheimia succiniciproducens MBEL 55E, from bovine rumen. Appl Microbiol Biotechnol 58:663-668. doi:10.1007/s00253-002-0935-6
4. Li Q, Siles JA, Thompson IP (2010) Succinic acid production from orange peel and wheat straw by batch fermentations of Fibrobacter succinogenes S85. Appl Microbiol Biotechnol 88:671-678. doi:10.1007/s00253-010-2726-9

5. Bechthold I, Bretz K, Kabasci S, Kopitzky R, Springer A (2008) Succinic acid: a new platform chemical for biobased polymers from renewable resources. Chem Eng Technol 31:647-654. doi:10.1002 /ceat.200800063

6. Song H, Lee SY (2006) Production of succinic acid by bacterial fermentation. Enzym Microb Technol 39:352-361. doi:10.1016/j. enzmictec.2005.11.043

7. Van der Werf MJ, Guettler MV, Jain MK, Zeikus JG (1997) Environmental and physiological factors affecting the succinate product ratio during carbohydrate fermentation by Actinobacillus sp. 130Z. Arch Microbiol 168:332-342

8. McKinlay JB, Vieille C, Zeikus JG (2007) Prospects for a bio-based succinate industry. Appl Microbiol Biotechnol 76:727-740. doi:10.1007/s00253-007-1057-y

9. Fiorentino N, Ventorino V, Rocco C, Cervinzio V, Agrelli D, Gioia L, Di Mola I, Adamo P, Pepe O, Fagnano M (2017) Giant reed growth and effects on soil biological fertility in assisted phytoremediation of an industrial polluted soil. Sci Total Environ 575:13751383. doi:10.1016/j.scitotenv.2016.09.220

10. Ventorino V, Aliberti A, Faraco V, Robertiello A, Giacobbe S, Ercolini D, Amore A, Fagnano M, Pepe O (2015) Exploring the microbiota dynamics related to vegetable biomasses degradation and study of lignocellulose-degrading bacteria for industrial biotechnological application. Sci Rep 5:8161. doi:10.1038/srep08161

11. Álvarez-Chávez CR, Edwards S, Moure-Eraso R, Geiser K (2012) Sustainability of bio-based plastics: general comparative analysis and recommendations for improvement. J Clean Prod 23:47-56. doi:10.1016/j.jclepro.2011.10.003

12. Ventorino V, Robertiello A, Viscardi S, Ambrosanio A, Faraco V, Pepe O (2016) Bio-based chemical production from Arundo donax feedstock fermentation using Cosenzaea myxofaciens BPM1. Bioresources 11:6566-6581

13. Kuhnert P, Scholten E, Haefner S, Fre J (2010) Basfia succiniciproducens gen. nov., sp. nov., a new member of the family Pasteurellaceae isolated from bovine rumen. Int J Syst Evol Microbiol 60:44-50. doi:10.1099/ijs.0.011809-0

14. Alfonzo A, Lo Piccolo S, Conigliaro G, Ventorino V, Burruano S, Moschetti G (2012) Antifungal peptides produced by Bacillus amyloliquefaciens AG1 active against grapevine fungal pathogens. Ann Microbiol 62:1593-1599. doi:10.1007/s13213-011-0415-2

15. Giacobbe S, Pepe O, Ventorino V, Leila B, Vinciguerra R, Faraco V (2014) Identification and characterisation of a pectinolytic enzyme from Paenibacillus xylanolyticus. Bioresources 9:4873-4887

16. Ventorino V, Sannino F, Piccolo A, Cafaro V, Carotenuto R, Pepe O (2014) Methylobacterium populi VP2: plant growth-promoting cacterium isolated from a highly polluted environment for polycyclic aromatic hydrocarbon (PAH) biodegradation. Sci World J . doi:10.1155/2014/9317932014:Article ID 931793

17. Thompson JD, Higgins DG, Gibson TJ (1994) CLUSTALW-improving the sensitivity of progressive multiple sequence alignment through sequence weighting, position-specific gap penalties and weight matrix choice. Nucleic Acids Res 22:4673-4680. doi:10.1093/nar/22.22.4673

18. Tamura K, Dudley J, Nei M, Kumar S (2007) MEGA4: molecular evolutionary genetics analysis (MEGA) software version 4.0. Mol Biol Evol 24:1596-1599. doi:10.1093/molbev/msm092

19. Ventorino V, Parillo R, Testa A, Aliberti A, Pepe O (2013) Chestnut biomass degradation for sustainable agriculture. Bioresources 8 : 4647-4658. doi:10.15376/biores.8.3.4647-4658

20. Pepe O, Ventorino V, Cavella S, Fagnano M, Brugno R (2013) Prebiotic content of bread prepared with flour from immature wheat 
grain and selected dextranproducing lactic acid bacteria. Appl Environ Microbiol 79:3779-3785. doi:10.1128/AEM.00502-13

21. Ventorino V, Parillo R, Testa A, Viscardi S, Espresso F, Pepe O (2016) Chestnut green waste composting for sustainable forest management: microbiota dynamics and impact on plant disease control. J Environ Manag 166:168-177. doi:10.1016/j.jenvman.2015.10.018

22. Marileo LG, Jorquera MA, Hernández M, Briceño G, de La Luz MM, Demanet R, Palma G (2016) Changes in bacterial communities by post-emergent herbicides in an Andisol fertilized with urea as revealed by DGGE. Appl Soil Ecol 101:141-151. doi:10.1016/j. apsoil.2016.02.003

23. Garbero M, Ottonello P, Cotti CM, Ferrero S, Torre P, Cherchi F, Bonanni A (2010) Improved biomass pretreatment process. Patent No WO 2010113129:A3

24. De Bari I, Liuzzi F, Villone A, Braccio G (2013) Hydrolysis of concentrated suspensions of steam pretreated Arundo donax. Appl Energy 102:179-189. doi:10.1016/j.apenergy.2012.05.051

25. Ghose TK (1987) Measurement of cellulase activities. Pure Appl Chem 59:257-268. doi:10.1351/pac198759020257

26. Becker J, Reinefeld J, Stellmacher R, Schafer R, Lange A, Meyer H, Lalk M, Zelder O, von Abendroth G, Schöder H, Haefner S, Wittmann C (2013) Systems-wide analysis and engineering of metabolic pathway fluxes in bio-succinate producing Basfia succiniciproducens. Biotechnol Bioeng 110:3013-3023. doi:10.1002/bit.24963

27. Pallant J (2013) SPSS survival manual, 5th edn. Open University Press, New Berkshire, England

28. Petri RM, Forster RJ, Yang W, McKinnon JJ, McAllister TA (2012) Characterization of rumen bacterial diversity and fermentation parameters in concentrate fed cattle with and without forage. J Appl Microbiol 112:1152-1162. doi:10.1111/j.1365-2672.2012.05295.x

29. Raja S, Dhanasekar R (2011) Succinic acid production from bovine rumen - isolation and optimization. Int J Chem Tech Res 3:19261931

30. Freitas CES, Almeida PNM, Duarte ER, Abrão FO, Careli R, Geraseev LC (2014) Aerobe and anaerobe facultative Gramnegative bacteria rod-shaped in the ruminal fluid of dairy cattle fed with different diets containing tropical forages. Arch Med Vet 46:457-462

31. Kim M, Wells JE (2016) A meta-analysis of bacterial diversity in the feces of cattle. Curr Microbiol 72:145-151. doi:10.1007 /s00284-015-0931-6

32. Zadoks RN, Griffiths HM, Munoz MA, Ahlstrom C, Bennett GJ, Thomas E, Schukken YH (2011) Sources of Klebsiella and Raoultella species on dairy farms: be careful where you walk. J Diary Sci 94:1045-1051. doi:10.3168/jds.2010-3603

33. Baltaci MO, Adiguzel A (2016) Isolation, identification and molecular characterization of cellulolytic bacteria from rumen samples collected from Erzurum Slaughter House, Turkey. Res J Biotechnol 11:32-38
34. Mao SY, Zhang ML, Liu JH, Zhu WY (2015) Characterising the bacterial microbiota across the gastrointestinal tracts of dairy cattle: membership and potential function. Sci Rep 5:16116. doi:10.1038 /srep16116

35. Di Pasqua R, Ventorino V, Aliberti A, Robertiello A, Faraco V, Viscardi S, Pepe O (2014) Influence of different lignocellulose sources on endo-1,4-B-glucanase gene expression and enzymatic activity of Bacillus amyloliquefaciens B31C. Bioresources 9: 1303-1310

36. Amore A, Pepe O, Ventorino V, Birolo L, Giangrande C, Faraco V (2013) Industrial waste based compost as a source of novel cellulolytic strains and enzymes. FEMS Microbiol Lett 339:93-101. doi:10.1111/1574-6968.12057

37. Amore A, Pepe O, Ventorino V, Aliberti A, Faraco V (2013) Cellulolytic Bacillus strains from natural habitats-a review. Chimica Oggi/Chemistry Today 31:49-52

38. Fiorentino N, Fagnano M, Adamo P, Impagliazzo A, Mori M, Pepe O, Ventorino V, Zoina A (2013) Assisted phytoextraction of heavy metals: compost and Trichoderma effects on giant reed (Arundo donax $\mathrm{L}$ ) uptake and soil N-cycle microflora. Ital J Agron 8:244 254. doi:10.4081/ija.2013.e29

39. Kim DY, Yim SC, Lee PC, Lee WG, Lee SY, Chang HN (2004) Batch and continuous fermentation of succinic acid from wood hydrolysate by Mannheimia succiniciproducens MBEL55E. Enzym Microb Technol 35:648-653. doi:10.1016/j. enzmictec.2004.08.018

40. Palmqvist E, Hahn-Hägerdal B (2000) Fermentation of lignocellulosic hydrolysates. I: inhibition and detoxification. Bioresour Technol 74:17-24. doi:10.1016/S0960-8524(99)00160-1

41. Scholten E, Haefner S, Schröder H (2014) Bacterial cells having a glyoxylate shunt for the manufacture of succinic acid. US Patent US8877466B2.

42. Ahn JH, Jang YS, Lee SY (2016) Production of succinic acid by metabolically engineered microorganisms. Curr Opin Biotechnol 15:54-66. doi:10.1016/j.copbio.2016.02.034

43. Pateraki C, Almqvist H, Ladakis D, Lidén G, Koutinas AA, Vlysidis A (2016) Modelling succinic acid fermentation using a xylose based substrate. Biochem Eng J 114:26-41. doi:10.1016/j. bej.2016.06.011

44. Pateraki C, Ladakis D, Stragier L, Verstraete W, Kookos I, Papanikolaou S, Koutinas A (2016) Pretreatment of spent sulphite liquor via ultrafiltration and nanofiltration for bio-based succinic acid production. J Biotechnol 233:95-105. doi:10.1016/j. jbiotec.2016.06.027

45. Salvachúa D, Smith H, St. John PC, Mohagheghi A, Peterson DJ, Black BA, Dowe N, Beckham GT (2016) Succinic acid production from lignocellulosic hydrolysate by Basfia succiniciproducens. Bioreour Technol 214:558-566. doi:10.1016/j.biortech.2016.05.018 